\title{
Praktik Bermusik Musisi Muda dalam Skena Metal Ekstrem
}

Oki Rahadianto Sutopo ${ }^{1}$, Agustinus Aryo Lukisworo

Youth Studies Centre (YouSure) dan Departemen Sosiologi Universitas Gadjah Mada

1Email : oki.rahadianto@ugm.ac.id

\begin{abstract}
Abstrak
Tulisan ini berfokus pada praktik bermusik musisi metal ekstrem muda di Yogyakarta dalam konteks era neoliberal. Guna membangun pengetahuan sesuai dengan narasi musisi metal ekstrem muda, penelitian ini menggunakan pendekatan kualitatif, secara spesifik etnografi, antara April hingga Agustus 2019. Untuk mengartikulasikan dimensi konfliktual dan hierarkisitas skena metal ekstrem, penelitian ini menggunakan perspektif Bourdieusian. Adapun hasil analisis temuan lapangan menunjukkan bahwa, pertama, secara objektif, praktik bermusik musisi muda dimulai dalam kondisi dimana kesenjangan sosial telah eksis bahkan sebelum praktik tersebut terjadi. Hal ini menunjukkan karakteristik skena metal ekstrem sebagai ranah perjuangan yang bersifat hierarkis -terbentang dari leval lokal, nasional hingga global. Kedua, secara teoritis, praktik bermusik musisi muda dalam skena metal ekstrem membutuhkan dan mereproduksi kapital yang sangat spesifik terkait dengan rule of the game dalam skena tersebut, kami menyebutnya sebagai 'kapital metal ekstrem'. Ketiga, muara dari proses akumulasi kapital metal ekstrem, kapital sosial dan kapital simbolik, serta proses embodiment mengenai kode-kode budaya terletak pada mekanisme reproduksi doxa skena metal ekstrem yang mengutamakan tiga nilai penting yaitu otentisitas, kemandirian dan komunitas. Adapun ketiga temuan tersebut merupakan manifestasi dari perlawanan skena metal ekstrem terhadap kuasa Negara dan pasar dalam era neoliberal.
\end{abstract}

Kata kunci : musisi muda, metal ekstrem, resistensi, praktik, Bourdieu

\section{Young Musicians Musical Practices in The Extreme Metal Scene}

\begin{abstract}
This article investigates the young extreme metal musicians' musical practices in Yogyakarta within the context of neoliberal era. To construct an empirical knowledge based on young extreme metal musicians' narratives, this research utilized qualitative approach, specifically ethnography, from April to August 2019. In order to articulate conflictual and hierarchical dimension of extreme metal scene, this research applied Bourdieusian perspective. Based on data analysis, this study shows that, firstly, objectively, young musicians' practices started within the condition which social inequality already existed. This represent a hierarchical characteristic of extreme metal scene as a field of struggle -ranging from local, national, to global level. Secondly, theoretically, young musicians' practices within extreme metal scene require and reproduce particular capital, with regard to the specific rule of the game of the extreme metal scene, defined as extreme metal capital. Thirdly, the goal of the extreme metal, social, and symbolic capital accumulation, also cultural codes embodiment, was on the extreme metal scene' doxa reproduction mechanism which accentuate three important values, namely authenticity, independency, and community. Finally, this three findings are the manifestation of extreme metal scene resistance towards state and market power in the neoliberal era.
\end{abstract}

Keywords : young musician, extreme metal, resistance, practice, Bourdieu 


\section{PENDAHULUAN}

Kajian mengenai musik populer dan budaya kaum muda dalam konteks Indonesia masih merupakan subjek yang termarjinalkan. Salah satu sebab kondisi ini terjadi adalah adanya hegemoni wacana pembangunan dan pertumbuhan ekonomi yang mewarnai kajiankajian ilmiah pada masa Orde Baru (Samuel 2010; Dhakidae, 2003). Terlepas dari kecenderungan tersebut, beberapa ilmuwan baik dari dalam maupun luar negeri berinisiasi melakukan kajian mengenai musik populer dan kaum muda dari berbagai macam subkultur dan genre, misalnya: reggae (Baulch, 2004), jazz (Sutopo, 2010; Sutopo and Nilan, 2018), indie (Luvaas, 2013), hardcore (Martin-Iverson, 2012), dangdut (Weintraub, 2010) dan metal (Baulch, 2003; Wallach, 2008). Secara garis besar, beberapa studi terdahulu tersebut membahas mengenai keterkaitan antara musik populer dengan konstruksi identitas lokal-global serta pusat-pinggiran, subkultur sebagai resistensi terhadap negara maupun komodifikasi serta terlekatnya senioritas dengan reproduksi sosial dalam komunitas musik. Kajian-kajian tersebut telah banyak memberikan kontribusi tidak hanya dalam 'menyelamatkan' dan 'mensuarakan' topik-topik yang bersifat marginal namun juga memberikan interpretasi alternatif mengenai pentingnya musik populer dan budaya kaum muda sebagai roda pendorong dan penggerak proses demokratisasi.

Disisi lain, dalam konteks perubahan sosial yang cepat dan massif, tidak dapat dinafikkan bahwa hegemoni neoliberal telah merasuk ke berbagai dimensi kehidupan (Springer, Birch and Macleavy, 2016) tidak terkecuali pada ranah musik. Salah satu manifestasi yang terlihat adalah komodifikasi serta infiltrasi logika pasar dalam produk budaya dimana musik menjadi salah satunya. Fenomena ini tidak hanya terjadi pada level global namun juga telah merasuk hingga ke level nasional dan lokal, tidak terkecuali di Indonesia. Berdasarkan penelusuran penulis, belum banyak kajian-kajian mengenai musik populer dan budaya kaum muda dalam konteks yang spesifik mengenai komodifikasi musik di Indonesia. Kajian yang sudah dilakukan misalnya Fahmi, McCann dan Koster (2017), Fahmi dan Koster (2017) serta Hanan dan Hemanto (2019) tidak membahas mengenai musik populer dan budaya kaum muda namun lebih kepada ekonomi kreatif. Oleh karena itu, artikel ini memiliki tujuan untuk melengkapi kekosongan tersebut dengan menggunakan titik masuk skena metal ekstrem dan musisi muda di Yogyakarta.

Secara spesifik, artikel ini membahas mengenai praktik musisi muda dalam skena ekstrem metal di Yogyakarta, Indonesia di tengah kondisi perubahan sosial yang cepat dan massif. Dengan menggunakan kerangka Bourdieusian (Bourdieu, 1993), 'praktik' yang dimaksud adalah proses dan strategi akumulasi kapital baik sosial, kultural maupun simbolik yang dilakukan musisi muda dalam ranah perjuangan yang khas merepresentasikan 'rule of the game' skena metal ekstrem. Secara spesifik, praktik bermusik termanifestasi dalam proses belajar (learning), bermain (playing), produksi (producing) dan mempertahankan (maintaining) nilai-nilai skena metal ekstrem yaitu otentisitas dan kemandirian di tengahtengah komodifikasi dan hegemoni neoliberal. Secara teoritis, berbeda dengan Becker dalam karyanya 'Art Worlds' (1982) yang terlalu menekankan pada aspek kerjasama dalam ranah budaya, kerangka berpikir Bourdieusian yang digunakan justru akan melihat dimensi konflik dan resistensi yang dilakukan oleh kaum muda pada skena metal ekstrem terutama saat berhadapan secara vis a vis dengan infiltrasi kuasa negara dan pasar. Poin tersebut menjadi kontribusi teoritis peneliti dalam artikel ini. Dalam konteks produksi pengetahuan, kajian dalam artikel ini ditempatkan dalam irisan antara studi musik populer (popular music) dan budaya kaum muda (youth culture) serta secara kritis dikontekstualisasikan pada pengalaman musisi muda Indonesia kontemporer.

\section{METODE PENELITIAN}

Penelitian ini menggunakan metode kualitatif terutama etnografi untuk memahami bagaimana musisi muda membentuk makna, melakukan praktik serta berpartisipasi dalam 
produksi kenyataan sehari-hari (Brewer, 2005) dalam skena metal ekstrem di Yogyakarta. Dengan kata lain, bagi kami, konteks sosiokultural serta kekhususan ranah produksi budaya menjadi aspek penting. Secara spesifik, kami menggunakan nongkrong sebagai titik masuk dalam memahami praktik bermusik merekadimana seringkali ketiadaan aktivitas yang berarti dalam skena justru menjadi poin penting guna membangun chemistry dan kedekatan baik antar musisi maupun antara peneliti dengan anggota skena musik tersebut (Sutopo, 2019). Dalam kegiatan nongkrong peneliti juga melakukan wawancara mendalam baik terstruktur maupun tidak terstruktur dengan mengambil berbagai setting lokasi antara lain di komunitas, after gigs, kampus dan tempat tinggal para musisi muda berdasarkan kesepakatan. Pemilihan riset empiris dalam kajian musik populer dan budaya kaum muda ini mengikuti pergeseran yang diusulkan oleh Muggleton (2000) dimana menurutnya memahami praktik bermusik dalam subkultur kaum muda tidak cukup hanya dengan pendekatan semiotik sebagaimana dilakukan oleh Hebdige (1979). Dengan melakukan riset empiris maka narasi subjektif (Bennett, 1999; Bennett et al, 2003) dari para pelaku dapat dimunculkan dan teori praktik (Bourdieu and Wacquant, 1992) dalam konteks ini dapat menjadi alat bantu guna memperlantang suara-suara musisi muda tersebut.

Penelitian ini dilakukan dari April hingga Agustus 2019 dengan mengambil lokasi di Yogyakarta. Total informan dalam penelitian ini adalah 15 musisi muda dari skena metal ekstrem. Pemilihan informan dilakukan secara purposif berdasarkan pengetahuan mendalam peneliti sebagai 'critical insiders' (Hodkinson, 2005) dalam skena musik di Yogyakarta. Secara ontologis, posisi ini berguna dalam mengetahui aturan main dalam ranah, memetakan siapa saja informan yang relevan serta bagaimana formasi hierarki dalam skena metal ekstrem tersebut berpengaruh dalam praktik bermusik di kehidupan sehari-hari. Semua informan dalam penelitian ini adalah laki-laki muda dikarenakan karakteristik skena metal ekstrem itu sendiri yang cenderung lebih bersahabat terhadap kultur maskulin dari masa ke masa. Data yang terkumpul baik dari catatan lapangan saat nongkrong maupun wawancara mendalam kemudian kami transkrip, seleksi, reduksi dan kategorikan berdasarkan tema-tema yang relevan dalam artikel ini.

\section{HASIL DAN PEMBAHASAN}

\section{Skena Metal Ekstrem Yogyakarta}

Skena metal ekstrem di Yogyakarta merupakan ruang yang terbentuk diantara para penggemar dan musisi yang juga berawal dari penggemar, dengan mayoritas latar belakang kelas menengah. Dengan mempertimbangkan relasi kuasa simbolis antar skena metal ekstrem dalam tataran global, skena metal ekstrem Yogyakarta sebagai bagian dari skena metal ekstrem Indonesia, berada pada posisi yang cenderung terisolir (Kahn-Harris, 2007). Oleh karena itu perkembangan musikal dalam skena metal ekstrem Yogyakarta cenderung mengikuti perkembangan musikal skena metal ekstrem global. Adapun proses distribusi berbagai varian musik metal ekstrem ke Yogyakarta, mulai dari thrash, speed, death, dan black metal, terjadi secara massal melalui distribusi artefak berupa kaset, $\mathrm{CD}$, dan merchandise yang dilakukan oleh beberapa distributor resmi di Indonesia, seperti salah satunya yaitu melalui PT Indosemarsakti. Selain itu, pada era Orde Baru, distribusi massal juga didukung dengan penyajian musik metal ekstrem oleh radio-radio lokal, seperti Bikima dan Geronimo, serta majalah-majalah cetak kaum muda, sejak akhir era 1980-an. Pada awalnya, konsumsi metal ekstrem lebih berkaitan dengan persoalan eksistensial, khususnya distingsi simbolis kaum muda (Wawancara Wanto, 2019). Dengan kata lain, secara teoritis, metal sebagai manifestasi kapital budaya untuk memproduksi distingsi dalam ranah perjuangan (Bourdieu, 1984). Dalam hal ini, narasi perkembangan awal metal ekstrem di Yogyakarta sejalan dengan temuan Wallach (2008) dalam studinya mengenai para penggemar musik metal di Jakarta, dimana metal ekstrem sebagai produk budaya barat dikonstruksikan sebagai sesuatu 'yang keren' 
dan lebih unggul dibandingkan dengan produk budaya lain yang bercorak lokal. Hal ini secara teoritis dapat dilihat sebagai manifestasi dari ranah produksi budaya yang mempunyai karakter hierarkis (Bourdieu, 1993) terbentang dari skena lokal, nasional dan global.

\begin{abstract}
"Merasa terpinggirkan? Enggak sih. Apa ya, bangga waktu itu saya rasanya, hahaha. Sering dulu zaman SMP waktu belum main band, akting main gitar pakai sapu sambil mendengarkan musik di radio, waaa, udah ngerasa sangar waktu itu, hahaha. Terus kalau ketemu dengan sesama penggemar metal ekstrem, sama-sama semangat. Kamu punya apa? Aku punya ini, saling tukar, rekamrekaman, sudah biasa waktu itu."

(Wawancara Wanto, 2019)
\end{abstract}

Selanjutnya, konsumsi metal ekstrem secara massal segera disusul dengan reproduksi metal ekstrem melalui band lokal yang dibentuk secara mandiri oleh para penggemar di Yogyakarta. Pada awalnya, praktik yang dilakukan para pelaku skena metal ekstrem berada dalam ruang yang sama dengan masyarakat umum. Hal ini direpresentasikan melalui penampilan band-band metal ekstrem Yogyakarta dalam berbagai pertunjukan seni '17-an' (Wawancara dengan Wanto, 2019). Namun demikian, memasuki awal tahun 1990an, terjadi benturan antara para pelaku metal ekstrem dengan warga yang umumnya lebih menggemari musik dangdut.

"Oh iya pernah dulu. Ya (warga) lebih senang musik dangdut, diminta dengar musik begini (extreme metal) ya enggak mau. Ya sudah dilempari dulu sama warga."

(Wawancara Wanto, 2019)

Selain berkaitan dengan aspek sonik, konstruksi metal ekstrem sebagai produk budaya yang dianggap tidak sesuai dengan normalitas kehidupan masyarakat, berkaitan dengan aspek verbal dan visual. Hal ini sebagaimana dijelaskan,

"Dulu sering Mas, kalau ada pertunjukan musik di JJ itu, kan lantai atasnya ada gereja, didatangi sama orang gereja, diajak ngobrol. Ditanya, kenapa kok tertarik mendengarkan musik seperti ini (identik dengan satanisme)?" (Wawancara Catur, 2019)
Dengan adanya benturan selera tersebut, praktik metal ekstrem di Yogyakarta pada akhirnya dilingkupi dengan persoalan politis dalam arti luas, khususnya terkait dengan gap aspirasi kaum muda dengan normalitas masyarakat Yogyakarta. Oleh karena itu, dalam perkembangan selanjutnya, di penghujung era Orde Baru, skena metal ekstrem kemudian menjadi semakin eksklusif. Hal ini secara teoritis menunjukkan pembentukan formasi sebagai subkultur ala Birmingham School yang melakukan resistensi melalui musik, fashion dan lifestyle (Hall and Jefferson, 1976). Lebih lanjut, hal ini ditandai oleh pembentukan komunitas metal pertama di Yogyakarta, Jogjakarta Corpse Grinder, pada tahun 1995, serta penyelenggaraan pertunjukan musik khusus metal ekstrem, Jogja Brebeg, setahun sesudah pendirian komunita. Sejak saat itu, pertunjukan langsung (live performance) metal ekstrem di Yogyakarta lebih terlokalisir dalam komunitas, dan diorganisir secara mandiri. Dengan kata lain, menunjukkan spirit Do It Yourself (DIY) yang harapannya tidak hanya merepresentasikan kemandirian dalam hal material, namun juga nilai-nilai idealisme atau resistensi.

Dalam kerangka Bourdieusian, praktik ini merupakan konstruksi awal akan rule of the game serta doxa yang menjadi normalitas (Bourdieu and Wacquant, 1992) dalam skena tersebut. Sementara interaksi antar pelaku, lebih banyak terjadi melalui aktivitas nongkrong malam minggu dalam komunitas tersebut (Clinton dan Wallach, 2016; Sutopo, 2019). Kemudian pada awal reformasi hingga pertengahan era 2000-an, intensitas praktik kultural metal ekstrem mengalami sedikit penurunan.

Hal ini sehubungan dengan adanya perkembangan tren musik alternatif dan keberhasilan beberapa band pop Yogyakarta meraih kontrak dengan label rekaman major di Indonesia (Wawancara dengan Yuda, 2019). Dalam medio tersebut, pertunjukan musik khusus metal ekstrem minim digelar di Yogyakarta. Namun demikian, relasi antar pelaku metal ekstrem di Yogyakarta tetap terjalin, karena itu di akhir era tahun 2000-an, 
skena metal ekstrem dapat 'muncul kembali'. Bahkan seiring dengan penampilan musik metal ekstrem di layar kaca, pada salah satu stasiun televisi swasta nasional, dan beberapa event musik 'umum' yang telah dilaksanakan di Yogyakarta, seperti Locstock tahun 2009. Pada akhir era 2000-an metal ekstrem mengalami popularisasi di kalangan kaum muda. Dalam situasi ini, metal ekstrem tidak lagi teridentifikasi sebagai produk budaya yang lekat dengan transgresivitas (Kahn-Harris, 2007), namun lebih sebagai produk kreatif kaum muda yang bersifat keren. Hal ini kemudian mendorong kaum muda di Yogyakarta untuk berbondong-bondong mengonsumsi metal ekstrem (Wawancara Tama, 2019). Namun hal tersebut tidak serta merta mendorong skena metal ekstrem Yogyakarta mengalami degradasi nilai idealisme dan kehilangan karakteristik khusus.

Hal ini terkait dengan adanya upaya dari para pelaku untuk menjaga skena metal ekstrem di Yogyakarta agar tetap distingtif, melalui apa yang disebut Wallach dan Levine (2011) sebagai 'boundaries patrol', sebagaimana ditunjukkan dalam kutipan wawancara berikut.

"Dulu pernah dibercandain waktu awal ikut nongkrong, 'sudah mendengarkan album apa saja? Suka beli rilisan enggak? Support tho itu namanya, jangan-jangan cuma download mp3 atau minta $m p 3$ ke temen'."

(Wawancara Putra 2019)

Mekanisme tersebut, merepresentasikan skena metal ekstrem sebagai ruang yang masih memerlukan penguasaan atas kompetensi kultural (Bourdieu, 1993), baik pengetahuan mengenai referensi musik maupun nilai kemandirian yang berlaku di dalam skena metal ekstrem. Berbeda dengan skena punk yang berpijak pada pengetahuan dalam bentuk politik kelas (Wallach dan Levine, 2011), kedua bentuk pengetahuan inilah yang menjadi pembeda antara pelaku otentik dengan pelaku yang minim otentisitas atau sering disebut 'poseur' dalam skena metal ekstrem. Secara teoritis, hal ini menunjukkan bagaimana pembentukan distingsi (Bourdieu, 1984) tidak hanya terkait dengan kaum muda di luar skena, namun juga antar metalhead di dalam skena itu sendiri melalui akumulasi subcultural capital (Thornton, 1996). Kemudian seiring dengan adanya reproduksi nilai simbolis kompetensi kultural dalam skena metal ekstrem tersebut, aktivitas nongkrong masih menjadi bagian dari habitus kolektif dalam skena metal ekstrem di Yogyakarta. Sebagaimana terjadi dalam skena musik lain, dalam aktivitas nongkrong tersebut para pelaku skena metal ekstrem Yogyakarta saling berbagi dan mengkonversi modal satu sama lain (Bourdieu, 1986). Mulai dari referensi musik hingga jaringan relasi dengan pelaku di skena metal ekstrem lain. Selain itu, penyelenggaran pertunjukan musik yang diorganisir secara mandiri juga masih dilakukan.

Meski demikian, pembedaan antar pelaku tidak hanya terhenti pada pemisahan antara 'yang otentik' dan 'yang tidak otentik', namun juga antar sesama pelaku yang terkonstruksi otentik. Dengan kata lain, relasi antar pelaku otentik di dalam skena metal tidak serta merta setara dan cenderung hirarkis. Dalam hal ini, selain kompetensi kultural, terdapat aspek relasi sosial serta rekognisi di dalam skena yang juga turut berpengaruh terhadap posisi sosial pelaku, termasuk musisi atau band.

Terkait hal ini, dalam konteks musisi atau band, para musisi metal ekstrem di Yogyakarta memiliki tantangan tersendiri, yang disebabkan oleh minimnya institusi skena berupa label rekaman independen di Yogyakarta. Adapun minimnya eksistensi label rekaman independen, yang berposisi sebagai 'cultural broker' (Bennett dan Waksman, 2014) atau penghubung produsen dan konsumen -khususnya di dalam skena metal ekstrem, bukan merupakan persoalan baru bagi para pelaku skena metal ekstrem di Yogyakarta, melainkan sudah terjadi sejak era 1990an (Wawancara Wanto, 2019). Dalam menghadapi situasi ini, terdapat dua pilihan tindakan yang biasa dilakukan oleh musisi/band metal ekstrem di Yogyakarta. Alihalih mencoba untuk membangun relasi dengan label rekaman major, opsi pertama yang biasa dilakukan adalah membangun kerjasama dengan label rekaman independen metal ekstrem di wilayah geografis lain. Namun demikian, opsi pertama tersebut sedikit sulit dilakukan tanpa 
didukung jaringan relasi yang kuat. Karena itu, terdapat opsi kedua yakni dengan menciptakan label fiktif atau tanpa label, dengan konsekuensi, proses produksi dan distribusi tetap dilakukan secara mandiri oleh musisi/band. Berbeda dengan institusi lain seperti zine komunitas beberapa diantaranya Megaton, Warhead, Enefa, dan Human Waste yang mulai eksis pada pertengahan menuju akhir era 1990an, serta Indogrind, zine online di era 2000an- dan distro -beberapa diantaranya Pleasure, Origin Merch, Warhead, Bowsound, Anthem, yang mulai muncul sejak pertengahan hingga akhir era 2000an, minimnya eksistensi label rekaman metal ekstrem di Yogyakarta belum mengalami perubahan, setidaknya hingga saat ini.

Selain itu, minimnya perubahan juga terjadi pada karakteristik praktik para musisi metal ekstrem Yogyakarta. Dalam hal ini, narasi praktik para musisi metal ekstrem Yogyakarta selaras dengan praktik musisi metal ekstrem dalam level global yang didominasi oleh profesionalisme-amatir. Meski didominasi oleh praktik yang bersifat melampaui amatirisme (Dummond, 1990) dan beberapa musisi bekerja dalam bidang yang berkaitan dengan skena metal ekstrem seperti usaha distro dan artworker, namun tidak atau belum terdapat musisi yang memosisikan praktik bermusik dalam skena metal ekstrem sebagai pekerjaan. Dengan kata lain, praktik musisi metal ekstrem Yogyakarta masih cenderung didominasi oleh nilai simbolik (non-ekonomi).

\section{Referensi Musik}

Sebagaimana dijelaskan di pendahuluan, praktik bermusik musisi muda yang dieksplorasi dalam artikel ini yaitu proses belajar (learning), bermain (playing), produksi (producing) dan mempertahankan (maintaining) dalam ranah produksi budaya yang bersifat hierarkis. Tiga sub-bab ke depan membahas mengenai praktik tersebut. Pertama, diperlukan pembahasan mengenai referensi sebagai salah satu bentuk modal kultural yang berpengaruh terhadap posisi agen (Bourdieu, 1986; 1993) di dalam skena metal ekstrem. Oleh karena itu, dapat dipahami bahwa proses akumulasi referensi musik merupakan tindakan substantif yang perlu 112 | J S P H dilakukan oleh para musisi metal ekstrem, sebagaimana dijelaskan:

"Logikanya begini, saya suka musiknya Opeth, kalau saya bikin musik yang sama persis seperti Opeth, terus buat apa orangorang mendengarkan musik saya, mending mereka mendengarkan musiknya Opeth aja. Makanya kita perlu referensi (musik) yang luas."

(Wawancara Ahmad, 2019)

Meski dalam era 2000an internet relatif lebih mudah diakses jika dibandingkan dengan era 1990an, namun pada umumnya akumulasi pengetahuan mengenai referensi musik masih melibatkan interaksi offline, face-to-face dengan para pelaku senior, baik musisi maupun non musisi. Dalam relasi tersebut, sebagai proses belajar, pemetaan sejarah dan perkembangan musik metal ekstrem dalam level global menjadi informasi dan pengetahuan berharga bagi musisi karena dapat digunakan sebagai landasan bagi proses akumulasi referensi musik secara mandiri di kemudian hari.

"Karena masih random, istilahnya pencarian lah... Saya tidak tahu ini band apa, jadi asal beli... Karena saya tertarik terus akhirnya sumbernya ya Pak Wanto itu, akhirnya ketemu semua band yang saya dengarkan ketika SMP, oh ini toh..."

(Wawancara Bagus, 2019)

Akumulasi pengetahuan mengenai sejarah dan perkembangan metal ekstrem diikuti dengan akumulasi referensi musik secara mandiri. Dalam proses ini, teknologi digital menjadi sarana pendukung sangat penting yang perlu dimanfaatkan secara optimal.

"Kalau namanya komunitas, menyatu dengan yang lain, mengonsumsi hal yang sama, dan berpikir dengan cara yang sama. Yang dibilang Eric Watain ya benar. Aku ngerasain gitu, sudah diberi tahu band yang benar ini, yang enggak benar ini, semuanya seragam... Dan pada akhirnya, saya runtut, zaman itu lah. Internet begitu penting, saya maksimalkan betul. Cari, ngulik, gini, gitu. Youtube aja aku, belum tahu bandcamp, belum tahu soundcloud, cuma youtube, paling sama metal-archive."

(Wawancara Tama, 2019)

Selanjutnya, seiring dengan kebutuhan untuk menciptakan karakter estetik khusus bagi produksi musik, eksplorasi atas referensi musik 
secara individual tidak hanya berhenti pada berbagai varian metal ekstrem saja, namun juga merambah beberapa genre musik lain, misalnya seperti punk. Hal ini dijumpai penulis ketika berkunjung ke rumah salah satu informan dan menemukan salah satu folder di dalam komputer informan yang berjudul, "I'm listening to punk now". Di dalam folder tersebut, penulis menjumpai berbagai mp3 dari berbagai band punk yang memiliki korelasi dengan metal ekstrem seperti Discharge -salah satu band punk Inggris era 1970an. Pola akumulasi referensi musik semacam ini, dinilai dapat memberikan keleluasaan bagi musisi untuk menciptakan karya yang memiliki 'nilai lebih', dengan kata lain meningkatkan nilai simbolik dari kapital budaya (Bourdieu, 1986; 1993). Hal ini dipertegas oleh pendapat Yuda yang bahkan memiliki pengalaman bermusik bersama band non-metal.

\begin{abstract}
"Dulu pernah punya pengalaman bantuin band profesional, disitu mataku kebuka, di band yang bukan metal aku dapet banyak pelajaran soal skena, soal pergerakan band-band'an, politik band-band'an, soal bagaimana bermain di musik lain yang di luar zona nyamanmu juga ternyata baik buat kesehatan mentalmu juga sebenarnya, untuk apa ya, kadang kalo kita mencari referensi untuk lagu A, kita ga melulu harus mencari sekitar A itu. Kadang kita bisa ke $\mathrm{Q}$ atau ke $\mathrm{K}$, atau $\mathrm{M}$ yang benerbener jauh, bahkan bukan ke $\mathrm{C}$ gitu. Ternyata ga masalah kayak gitu, dan lebih intense lagi untuk mendengar banyak musik dan hubungannya dengan sejarahnya, manusianya, skena, memperhatikan skena, bagaimana anak-anak non metal itu berpikir, bergerak, gimmick apa yang mereka pakai, itu banyak aku pelajari dan aku aplikasikan di bandku yang metal."

(Wawancara Yuda, 2019)
\end{abstract}

Lebih lanjut, dengan eksplorasi musik sebagai representasi proses bermain (playing) dan produksi (producing) yang relatif luas dan bervariasi, para musisi memiliki peluang yang lebih besar untuk dapat meraih rekognisi di dalam skena metal ekstrem. Hal ini sebagaimana dijelaskan,

"Dulu waktu saya ngirim contoh album saya ke Dunkelheit (label rekaman independen metal ekstrem asal Jerman), mereka langsung komentar, 'oh ada juga ya band Indonesia yang memainkan death metal yang seperti ini. Saya pikir death metal (corak) Florida semua, dengan sound bersih dan 'clear'. Dan saya pikir, hal itu merupakan salah satu alasan mengapa Dunkelheit mau merilis band saya." (Wawancara Tama, 2019)

Dengan demikian, dapat dijelaskan bahwa pengetahuan berupa referensi musik sebagai representasi dari kapital budaya (Bourdieu, 1986) dan subcultural capital (Thornton, 1996) merupakan landasan bagi para musisi untuk dapat menciptakan karya yang 'otentik' dan 'bernilai tinggi'. Dalam tahap selanjutnya, karya tersebut dapat digunakan untuk oleh para musisi untuk meraih rekognisi di dalam skena metal ekstrem. Kemudian berkaitan dengan sisi kompetitif skena metal ekstrem, maka para musisi dituntut untuk menampilkan karakteristik khusus atau keunikan melalui karya yang dihasilkan, sehingga akumulasi secara mandiri perlu dilakukan oleh masing-masing musisi.

\section{Relasi Sosial dan Rekognisi}

Selain referensi musik, relasi dan rekognisi juga merupakan dua aspek penting yang saling beririsan dan menjadi fondasi bagi praktik bermusik para informan di dalam skena metal ekstrem. Selaras dengan akumulasi referensi musik, proses akumulasi relasi dan rekognisi di dalam skena metal ekstrem juga diawali tindakan-tindakan secara offline, khususnya dengan bergabung pada komunitaskomunitas musik lokal yang ada di Yogyakarta. Hal ini sebagaimana dijelaskan

"Dulu itu saya kalau melihat skena-skena metal luar rasanya seperti jauh sekali. Walaupun ada Mas Menus atau Mas Rudi yang suka main di luar... Karena mereka kan sudah lama di sini (skena), lebih lama daripada kita lah... Ya sepertinya rata-rata kita semua ini awalnya seperti itu deh, kalau tidak nongkrong, tidak bergabung ke komunitas ya tidak memperoleh kesempatan untuk tampil, tidak bisa mengenal orang lain."

(Wawancara Ahmad, 2019)

Lebih lanjut, terkait dengan bergabungnya para musisi dalam komunitas musik lokal Yogyakarta, sebagaimana terepresentasikan oleh pendapat Ahmad, proses bermain (playing), secara spesifik penampilan langsung (live performance) dalam pertunjukan musik 
komunitas merupakan titik masuk atau langkah awal untuk dapat diterima sebagai bagian dalam skena metal ekstrem, atau dengan kata lain, untuk meraih rekognisi awal dalam ranah produksi budaya (Bourdieu, 1993). Namun demikian, penampilan langsung saja tidak cukup sebagai manifestasi akumulasi kapital dan mempertahankan (maintaining) posisi dalam ranah yang bertingkat, sehingga harus ditopang dengan praktik produksi album. Hal ini sebagaimana dijelaskan

"Sekarang kan paling enak coba kita look back. Bandku itu kapan sih dianggep, kecuali habis rilis full album pertama, pada bingung (karena berani dan dapat memproduksi album). Sebelum itu apa sih... Karena apa, nobody bro."

(Wawancara Tama, 2019)

Kemudian sebagaimana telah dijelaskan, memperoleh dukungan dari label rekaman menjadi sebuah tantangan tersendiri bagi para musisi metal ekstrem Yogyakarta, sehubungan dengan minimnya keberadaan label rekaman independen metal ekstrem di Yogyakarta. Hal ini dalam kerangka Bourdieusian (1993) menunjukkan kenyataan objektif dimana ranah produksi budaya bersifat hierarkis, distribusi kapital tidak merata serta titik awal posisi sosial agen yang tidak setara dalam berjuang (struggle). Sementara itu, relasi dengan label rekaman merupakan salah satu aspek penopang kemandirian dan rekognisi bagi musisi/band di dalam skena metal ekstrem. Tanpa relasi dengan label rekaman, musisi/band harus melakukan proses produksi dengan mengandalkan modal ekonomi pribadi, serta proses distribusi secara mandiri. Sedangkan alternatif lain yang dapat ditempuh untuk memperoleh dukungan bagi proses produksi dan distribusi album, adalah dengan membentuk relasi secara online (korespondensi) dengan label rekaman metal ekstrem independen di wilayah geografis lain, termasuk luar Indonesia. Namun demikian, pembentukan relasi dengan label rekaman independen secara online, tidak dapat dilakukan dengan begitu saja.

"Ya kan ada internet, saya bisa bahasa Inggris, dan saya punya album. Kenapa saya tidak coba kontak orang-orang baru. Tapi ya saat itu saya sudah bisa kira-kira, kalau untuk ngontak label seperti Hellsheadbanger (label metal ekstrem dengan reputasi 'tinggi') gitu ya enggak berani saya. Label yang kecil-kecil saja banyak yang menolak, bilang kalau cuma bisa rilis band sana (Eropa/Amerika) lah, cuma mau rilis band yang bisa tur durasi panjang lah."

(Wawancara Tama, 2019)

Sebagaimana ditunjukkan dalam kutipan wawancara di atas, tampak bahwa para musisi harus berhadapan dengan hierarkisitas skena metal ekstrem dalam level global, dimana selera dan rekognisi menjadi modal yang penting dan krusial untuk dapat dikonversikan ke dalam bentuk modal sosial berupa relasi dengan label rekaman independen. Namun selain itu, kemampuan untuk berkomunikasi dan berdiplomasi juga menjadi modal yang diperlukan untuk dapat membangun relasi, dalam hal ini label rekaman independen di luar Indonesia, sebagaimana dijelaskan.

"Kalau tidak terbiasa bikin obrolan susah juga sih. Apalagi selain bahasa, cara berpikirnya, kebiasaannya beda sama kita. Tapi kalau tidak saya, siapa lagi, karena personel band tidak ada yang terbiasa (melakukan korespondensi) juga. Karena waktu awal mau nyoba ngontak label itu minta screenshot obrolan teman saya sama label dia. Saya pengen tahu gimana sih pendekatan dia ke label, kata-kata yang dipakai itu gimana gitu lho."

(Wawancara Ahmad, 2019)

Perlu dicatat pula bahwa relasi sosial dalam level lokal juga menjadi modal lain yang dapat digunakan untuk mendukung proses akumulasi modal sosial, dan tentu saja rekognisi, di dalam skena metal ekstrem. Dalam hal ini, relasi pada level lokal merepresentasikan 'modal sosial durable' (Sutopo, Threadgold \& Nilan, 2017), atau modal sosial yang telah terbentuk dan dipertahankan oleh para musisi dalam jangka waktu yang panjang. Lebih lanjut, modal sosial durable tersebut merupakan produk dari aktivitas nongkrong (Sutopo, 2019) sebagai sebuah bagian dari skena metal ekstrem Yogyakarta yang tetap dipertahankan hingga saat ini. Sebagaimana telah dijelaskan sebelumnya, dalam aktivitas inilah para musisi saling berbagi modal kepada lainnya, mulai dari referensi musik hingga relasi/jaringan dengan 
para pelaku dari skena metal ekstrem di wilayah yang lain.

\section{Kemampuan Teknis Bermusik}

Meski bukan menjadi fondasi utama, kemampuan teknis bermusik juga merupakan kapital budaya (Bourdieu, 1986) yang diperlukan untuk dapat membangun praktik bermusik. Selaras dengan penjelasan KahnHarris (2007) mengenai metal ekstrem sebagai musik yang tidak memprioritaskan tingkat penguasaan teknis, sebagian musisi metal ekstrem di Yogyakarta melihat kemampuan teknis sebagai representasi dari profesionalitas nilai yang berlawanan dengan otentisitas pelaku di dalam skena. Namun demikian, secara implisit metal ekstrem menuntut adanya penguasaan teknis bermusik, khususnya kemampuan teknis bermusik yang hanya berlaku di dalam skena metal ekstrem saja. Misalnya teknik 'double time skank beat' yang menjadi karakteristik teknis drum thrash metal, serta teknik 'blasting' untuk drum death metal. Kemudian teknik 'palm mute rythm' untuk gitar thrash metal, serta 'growl' dan 'throat' untuk teknik vokal. Selain itu, realitas mengenai para pelaku di Eropa yang diuntungkan dengan adanya mekanisme subsidi negara bagi warga negara yang hendak melakukan kursus musik, termasuk metal ekstrem (Kahn-Harris, 2007), juga perlu dipertimbangkan dalam hal ini. Karena itu terdapat pula sebagian musisi metal ekstrem yang menilai kemampuan teknis sebagai modal yang perlu diakumulasikan.

"Ya konsep itu penting, tapi klo mainnya enggak oke, gimana? Jadi ya menurutku kita berusaha main bagus aja deh. Nanti juga pasti ada yang ngasih apresiasi kok."

(Wawancara Johan, 2019)

Terkait hal ini, meski mayoritas musisi metal ekstrem Yogyakarta mengakumulasikan kemampuan teknis bermusik secara otodidak, sempat terdapat sesi sharing kemampuan teknis dalam sebuah agenda komunitas yang tergolong semi-formal dan melibatkan musisi senior di dalam skena metal ekstrem Yogyakarta yang memberikan kontribusi cukup signifikan bagi akumulasi kemampuan teknis bermusik para informan. Walaupun pada akhirnya agenda tersebut tidak dilakukan secara rutin dan berkelanjutan.

"Ya dulu kan sempat ada semacam gitar klinik sama musisi senior, tapi ya enggak lanjut. Padahal lumayan membantu itu, dari skillku 100\%, 60\% aku dapat dari situ. Misalnya, dari situ jadi tahu soal apa itu, teknik 'downstroke' itu, triol? Hahaha... Walaupun ya cuma sedikit."

(Wawancara Tama, 2019)

Secara struktural, ketidakberlanjutan dari sesi sharing kemampuan teknis tersebut terkait dengan kehidupan non-skena para musisi metal Yogyakarta. Dalam hal ini, biasanya sesi sharing dilakukan malam hari di hari kerja, agar tidak berbenturan dengan aktivitas nongkrong yang secara rutin dilakukan pada malam minggu. Sementara para musisi metal ekstrem Yogyakarta didominasi oleh musisi profesionalamatir, yang memiliki pekerjaan di luar aktivitas bermusik. Akibatnya, sulit untuk menemukan kesamaan waktu antar musisi (Wawancara Tama, 2019). Dengan kondisi tersebut, akumulasi kemampuan teknis bermusik lebih banyak dilakukan dalam secara mandiri, sesuai dengan kebutuhan konsep musik yang dimainkan.

"Aku awalnya ga ngerti tuh mas teknisnya, itu aku diajarin waktu ikut komunitas musik di kampusku. Pacarnya temen bandku ada yang penyanyi terkenal, jazz, maksudnya di kalangan jazznya jogja, dia bangun itu loh sekolah vokal juga sekarang. Biasanya yang ngajarin aku dia, ngatur nafas, kalo nyanyi lirik itu penting, lafalnya, pokoknya jangan takut muka jelek, kalo memang itu nada rendah tuh, menunduk itu ternyata membantu... Temen aku penyanyi juga, aku surrounded by kalo di temen kampus rata-rata penyanyi, solois... Awalnya temen deket ada cewek, dia dulu awalnya berangkat dari rock, metal, tapi jadi pop abis itu karena ngikutin pasar, karena dia sering reguleran di cafe. Dulu waktu dia di sini, sebelum lulus. Nah itu temen deketku, aku belajar dari dia. Karena dia emang kalo ikut kontes gitu menang mas, solo, suaranya bagus banget, belajar dari dia kebanyakan, dan itu kepake semua di band." (Wawancara Putri, 2019)

Sejauh ini, selain informan yang memang menempuh pendidikan dalam bidang musik, proses akumulasi kemampuan teknis bermusik lebih banyak melibatkan modal sosial yang 
termanifestasi dalam relasi personal individual, baik di dalam maupun di luar skena. Hal ini terepresentasikan melalui penjelasan Putri di atas yang mengkolaborasikan relasi di dalam band dengan lingkungan pertemanan di institusi pendidikan tinggi. Tidak dijumpai informan yang sengaja mengikuti kursus musik untuk mengakumulasikan kemampuan teknis-teknis bermusik. Secara teoritis, dapat dijelaskan bahwa strategi yang dilakukan musisi muda untuk mengakumulasi kapital budaya secara spesifik yaitu kapital metal ekstrem adalah melalui konversi modal sosial (Bourdieu, 1986; Sutopo, Threadgold \& Nilan, 2017) secara fleksibel didalam maupun di luar skena.

\section{Refleksi Teoritis Praktik Bermusik Musisi Muda dalam Skena Metal Ekstrem}

Berdasarkan temuan empiris dan dialog dengan kerangka Bourdieusian (1993), kami melakukan refleksi teoritis, abstraksi dan memformulasikan tiga novelty (kebaruan) mengenai praktik bermusik musisi muda pada skena metal ekstrem dalam konteks perubahan sosial yang cepat dan masif. Pertama, secara objektif, praktik bermusik musisi muda dimulai dalam kondisi dimana kesenjangan sosial telah eksis bahkan sebelum praktik tersebut terjadi. Dalam kerangka Bourdieusian (1993), hal ini menunjukkan karakteristik ranah perjuangan yang bersifat hierarkis secara spesifik dalam ranah produksi budaya, hierarki tersebut terbentang dari leval lokal, nasional hingga global. Kondisi kesenjangan tersebut membawa implikasi mutlak dimana distribusi kapital baik budaya, sosial, ekonomi maupun simbolik (Bourdieu, 1986) tidak terdistribusi secara merata baik secara objektif antar posisi sosial dalam ranah maupun secara individual bagi agensi sosial.

Musisi muda sebagai representasi dari agensi sosial yang berkarakter 'accumulative being' harus berjuang untuk mengakumulasi kapital yang berharga tersebut tidak hanya untuk bertahan, namun juga mencapai progress berdasarkan 'rule of the game' skena dalam level lokal, nasional dan global (Sutopo, Wibawanto \& Lukisworo, 2020). Dalam hal ini, skena metal ekstrem tidak terlepas dari 116 | J S P H reproduksi ketimpangan dan kesenjangan tersebut. Disisi lain, perubahan sosial, komodifikasi serta hegemoni neoliberal misalnya terkait dengan perkembangan teknologi informasi menjadi sumber kapital budaya dan sosial 'baru' yang juga penting untuk dikombinasikan dengan kapital dalam ranah 'offline' guna berjuang dalam himpitan hierarki skena metal ekstrem dari lokal, nasional hingga global. Dalam hal praktik bermusik, manifestasinya terlihat pada setiap proses dari belajar (learning), bermain (playing), produksi (producing) dan mempertahankan (maintaining) sebagaimana telah dijelaskan secara detail dalam tiga sub-bab diatas.

Kedua, secara teoritis, praktik bermusik musisi muda dalam skena metal ekstrem membutuhkan dan mereproduksi kapital yang sangat spesifik terkait dengan rule of the game (Bourdieu, 1993) dalam skena tersebut, kami menyebutnya dengan istilah 'kapital metal ekstrem'. Bentuk kapital ini merupakan inovasi dan pengembangan dari kapital budaya dari Bourdieu (1986) dan juga kapital subkultural (Thornton, 1996) namun dengan konteks spesifik skena metal ekstrem. Berbeda dengan kapital budaya dari Bourdieu (1986) yang termanifestasi menjadi tiga yaitu objectified, institutionalized dan embodied, serta kapital subkultural dari Thornton (1996) yang mendasarkan pada konteks gaya hidup clubbing; bagi kami, kapital metal ekstrem termanifestasi melalui dua wujud. Yang pertama yaitu referensi dan teknik bermusik, misalnya teknik drum thrash metal 'double time skank beat', teknik 'blasting' untuk drum death metal ataupun teknik 'palm mute rythm' untuk gitar thrash metal, serta teknik vokal 'growl' dan 'throat'. Kedua, kode-kode subkultur terkait mana yang dianggap otentik dan bernilai 'tinggi', mana yang original dan mana yang hanya 'poseur'. Kedua aspek tersebut diakumulasi melalui proses yang bersifat otodidak, bertumpu pada penubuhan (embodiment) yang harus terus menerus dilakukan dan dirawat, serta dilanggengkan melalui prinsip berbagi (sharing) terutama di dalam skena metal ekstrem. 
Kapital budaya yang bersifat institutionalized (Bourdieu, P. 1986) misalnya, tidak mempunyai nilai konversi yang tinggi dalam skena. Lebih lanjut, bentuk kapital metal ekstrem diproduksi dan direproduksi secara turun temurun sebagai mekanisme mempertahankan doxa dalam skena, meskipun improvisasi masih dimungkinkan dalam taraf tertentu oleh generasi musisi muda metal ekstrem yang berbeda. Lebih lanjut, 'kapital metal ekstrem' yang kami usulkan secara khusus dapat dikonversi di dalam ranah budaya terutama skena metal ekstrem itu sendiri. Namun, bukan berarti tingkat keberlakuannya hanya bersifat terbatas atau 'lokal' dalam skena saja, namun dalam kasus-kasus tertentu, terlepas dari hierarki yang eksis, kapital metal ekstrem 'lokal' dapat dikonversikan untuk bernegosiasi dengan 'rule of the game' skena metal ekstrem pada level global serta melakukan mobilitas sosial ke atas secara simbolik.

Ketiga, muara dari proses akumulasi kapital metal ekstrem, kapital sosial dan kapital simbolik serta proses embodiment mengenai kode-kode budaya merupakan mekanisme reproduksi doxa skena metal ekstrem yang mengutamakan tiga nilai penting yaitu otentisitas, kemandirian dan komunitas. Ketiganya merupakan nilai-nilai yang dipegang teguh dan menjadi landasan bersama bagi keberlanjutan skena metal ekstrem dari masa ke masa. Tidak hanya itu, dalam konteks komodifikasi dan hegemoni neoliberal baik yang dilakukan oleh Negara maupun pasar, ketiga nilai tersebut merupakan manifestasi dari resistensi skena metal ekstrem. Bagi mereka, 'menghidupi skena' jauh lebih penting daripada tunduk terhadap kuasa Negara dan pasar. Di sisi lain, menurut kami, hal ini juga menunjukkan bagaimana budaya kaum muda (youth culture) masih menjadi 'ruang' yang relevan dan penting untuk melakukan perlawanan baik yang termanifestasi dalam praktik maupun secara simbolik. Secara teoritis, reproduksi tiga nilai idealisme dalam skena metal ekstrem ini kami maknai pula sebagai kembalinya dimensi 'politik' dalam musik populer dan budaya kaum muda. Musik dan praktik bermusik kaum muda harus tetap 'berisik' dan 'kritis'; jangan biarkan Negara dan Pasar tertidur lelap!

\section{PENUTUP}

Artikel ini membahas mengenai praktik bermusik musisi muda dalam skena metal ekstrem di Yogyakarta. Praktik bermusik tersebut dikontekstualisasikan dengan kondisi kontemporer masyarakat berupa perubahan sosial, komodifikasi serta hegemoni neoliberal di Indonesia. Di sisi lain, artikel ini menggunakan kerangka Bourdieusian untuk menunjukkan bagaimana hierarki masih direproduksi secara terus menerus dalam level lokal, nasional, dan global, serta memotret pentingnya dimensi konflik dan resistensi dalam skena metal ekstrem.

Praktik bermusik musisi muda kemudian direfleksikan secara teoritis untuk diusulkan tiga kebaruan yaitu mengenai kesenjangan sosial sebagai existing social conditions, formulasi 'kapital metal ekstrem' yang berbeda dari kapital budaya dan kapital subkultural, serta reproduksi doxa skena metal ekstrem dalam pengutamaan tiga nilai idealis yang penting: otentisitas, kemandirian dan komunitas. Bagi kami, ketiganya merupakan manifestasi perlawanan skena metal ekstrem terhadap kuasa Negara dan pasar dalam era neoliberal.

\section{DAFTAR RUJUKAN}

Baulch, E. (2003). Gesturing Elswhere: the Identity Politics of Balinese Death/Trash Metal Scene. Popular Music 22(2), 195215.

Baulch, E. (2004). Reggae Borderzones, Reggae Graveyards: Bob Marley Fandom in Bali. Perfect Beat: The Asia-Pacific Journal of Research into Contemporary Music and Popular Culture 6(4), 3-27.

Becker, H. (1982). Art Worlds. USA: University of California Press.

Bennett, A., dan S. Waksman. (2014). The SAGE Handbook of Popular Music. California: Sage.

Bennett, A., M. Cieslik., and S. Miles, (eds). (2003). Researching Youth. New York: Palgrave Macmillan. 
Bennett, A. (1999). "Subcultures or Neo-tribes? Rethinking the Relationship between Youth, Style and Musical Taste". Sociology 33(3): 599-617.

Bourdieu, P. (1984). Distinction: A Social Critique of the Judgement of Taste. USA: Harvard University Press.

Bourdieu, P. (1986). The Forms of Capital. Dalam J. Richardson (ed), Handbook of Theory and Research for the Sociology of Education (Hal. 241-258). Wesport CT: Greenwood.

Bourdieu, P. (1993). The Field of Cultural Production: Essays on Art and Literature. New York: Columbia University Press.

Bourdieu, P dan L. Wacquant. (1992). An Invitation to Reflexive Sociology. USA: Chicago University Press.

Brewer, J. (2005). Ethnography. Buckingham: Open University Press.

Clinton, E. dan J. Wallach. (2016). Talking Metal: The Social Phenomenology of Hanging Out. Dalam Nelson Varas-Diaz dan Nial Scott (ed), Heavy Metal Music and the Communal Experience (Hal. 3756). Lanham: Lexington Books.

Dhakidae, D. (2003). Cendekiawan Dan Kekuasaan Dalam Negara Orde Baru. Jakarta: Gramedia Pustaka Utama.

Dummond, J.D. (1990). The Characteristics of Amateur and Professional. International Journal of Music Education, 15, 3-8.

Fahmi, F.Z., P. McCann, and S. Koster. (2017). Creative Economy Policy in Developing Countries: the Case of Indonesia. Urban Studies 54(6), 1367-1384.

Fahmi, F.Z., and S. Koster. (2017). Creative Industries and Regional Productivity Growth in the Developing Economy: Evidence from Indonesia. Growth and Change 48(4), 805-830.

Hall, S., and T. Jefferson (ed). (1976). Resistance through Rituals: Youth Subcultures in Post-War Britain. London: Routledge.

Hanan, H., and D. Hemanto. (2019) From Clothing to Culinary Industries: Creativity in the Making of Place. Creative
Industries Journal (online first).

Hebdige, D. (1979). Subculture: the Meaning of Style. London: New Accents.

Hodkinson, P. 2005. "Insider Research in the Study of Youth Cultures". Journal of Youth Studies 8(2), 131-149.

Kahn-Harris, K. (2007). Extreme Metal Music and Culture on the Edge. Oxford: Berg.

Luvaas, B. (2013). DIY Style: Fashion, Music and Global Digital Cultures. Oxford: Berg.

Martin-Iverson, S. (2012). Autonomous Youth? Independence and Precariousness in the Indonesian Underground Music Scenes. The Asia Pacific Journal of Anthropology 13(4), 382-397.

Muggleton, D. (2000). Inside Subculture: Postmodern Meaning of Style. Oxford: Berg.

Samuel, H. (2010b). "Universitas, Negara Dan Masyarakat Indonesia: Implementasi Paradigma Modernisasi Di Era Orde Baru." Humaniora 22, 31-42.

Springer, S., K. Birch., dan J. Macleavy (ed).(2016). The Handbook of Neoliberalism. London: Routledge.

Sutopo, O.R. (2010). Dinamika kekuasaan dalam Komunitas Jazz Yogyakarta 20022010. Jurnal Ilmu Sosial dan Ilmu Politik 14(1), 83-106.

Sutopo, O. (2016). Agenda Pengembangan Kajian Kepemudaan di Indonesia. Jurnal Sosiologi Pendidikan Humanis, 1(2), 161172. Retrieved from http://journal2.um.ac.id/index.php/jsph/art icle/view/2472

Sutopo, O.R. (2019). 'Learning by Doing: Young Indonesian Musicians, Capital and Night Life.' Dalam Geoff Stahl dan Giacomo Botta (ed), Nocturnes: Popular Music and the Night, 79-94, UK: Palgrave.

Sutopo, O. R., S. Threadgold, dan P. Nilan. (2017). Young Indonesian Musicians, Strategic Social Capital, Reflexivity, and Timing. Sociological Research Online, 22(3), $186-203$.

Sutopo, O.R., and P. Nilan. (2018). The 
Constrained Positions of Young Musicians in the Yogyakarta Jazz Community. Asian Music 49(1), 34-57.

Sutopo, O.R., G.R. Wibawanto dan A.A Lukisworo. (2020). Melampaui Subkultur/Post-Subkultur: Musisi sebagai Jalan Hidup Kaum Muda. Jurnal Studi Pemuda 9(1): 1-12.

Thornton, S. (1996). Club Cultures: Music, Media and Subcultural Capital. USA: Wesleyan University Press.

Wallach, J. (2008). Modern Noise, Fluid Genres? Popular Music in Indonesia, 1997-2001. Wisconsin: The University of Wisconsin Press.
Wallach, J \& A. Levine. (2011). 'I want you to support local metal': A theory of metal formation. Popular Music History, 6.1/ 6.2, 116-134.

Weintraub, A. (2010). Dangdut Stories: A Social and Musical History of Indonesia's Most Popular Music. New York: Oxford University Press 